\title{
FORMAÇÃO CONTINUADA DE PROFESSORES DA EDUCAÇÃO BÁSICA E O ENSINO DAS CIÊNCIAS NATURAIS ${ }^{1,2}$
}

Silmara Sartoreto de Oliveira ${ }^{3}$ Fernando Bastos ${ }^{4}$

\section{RESUMO}

Este estudo busca identificar o perfil educacional dos professores do ensino fundamental das séries iniciais. Seu objetivo é fornecer situações reflexivas onde os professores possam discutir sobre sua própria formação. Os dados foram obtidos a partir das respostas de onze professores de escola pública à um questionário. Também foram realizados encontros quinzenais com esses professores que formaram um Grupo de Trabalho, onde estes encontros foram filmados, transcritos e analisados. Durante a pesquisa verificou-se haver problemas pedagógicos no processo de ensino aprendizagem, no método de ensino adotado, no estabelecimento e valorização da relação professor-aluno e na interação entre os alunos quando da construção do conhecimento científico. No final do estudo, entendeu-se que os profissionais pesquisados apresentam falhas em sua formação como professores; não participam de cursos de atualização; e quando enfrentam dificuldades de entendimento em como lidar com algum conteúdo científico com os alunos, os professores pesquisam em livros escolares para sanar suas dúvidas. Os professores também apontaram que os cursos de atualização promovidos pela Diretoria de Ensino são considerados muito teóricos e pouco práticos, e não apresentam nenhuma ligação com o contexto em que os professores estão inseridos.

Palavras-Chave: formação continuada, ensino de ciências

\section{INTRODUÇÃO}

Ao longo da história da educação, no Brasil, muitos trabalhos enfocam o processo de ensino e aprendizagem escolar. Porém, o desenvolvimento de pesquisas, na área de formação continuada de professores que envolvem a área das ciências naturais, ainda é pouco explorado.

Para o aprofundamento teórico, neste artigo alguns temas foram considerados, tais como: o que o professor da educação básica, das séries iniciais, abordam como conteúdos de ciências; utilizam teorias e metodologias de ensino que embasam a sua prática pedagógica, e qual a formação continuada que o professor deseja e necessita, para trabalhar na área das ciências naturais.

Baseados em uma proposta de formação continuada, esses temas apontam para uma pesquisa qualitativa do ponto de vista educacional, em que se buscou investigar como os professores do ensino fundamental das séries iniciais enfrentam e constroem o processo de

\footnotetext{
${ }^{1}$ Apoio CAPES

${ }^{2}$ Este artigo representa parte de uma pesquisa intitulada: Formação Continuada de professores de $1^{\mathrm{a}}$ a $4^{\mathrm{a}}$ séries do ensino fundamental na área de ciências: realidades e necessidades docentes, em nível de Doutorado em Educação para a Ciência, Faculdade de Ciências/UNESP/Bauru.

${ }^{3}$ Doutoranda em Educação para a Ciência Faculdade de Ciências - Unesp/Bauru sartoret@fc.unesp.br Grupo de Pesquisa em Ensino de Ciências - UNESP/Bauru

${ }^{4}$ Docente do Programa de Pós-Graduação em Educação para a Ciência Faculdade de Ciências - Unesp/Bauru fernando_bastos2005@ig.com.br Grupo de Pesquisa em Ensino de Ciências - UNESP/Bauru
} 
ensino e aprendizagem, em sala de aula, e quais estratégias se utilizam para os conteúdos de ciências.

Por considerar que as transformações do sistema educacional são lentas e gradativas, e que muitos professores continuam sendo submetidos ao processo de formação inicial de forma deficitária, procurou-se investigar como um grupo de professores do ensino fundamental das séries iniciais, do sistema público de ensino e como este enfrenta o processo de ensino e aprendizagem das ciências naturais, em sala de aula.

Assim, esta pesquisa, realizada em nível de doutorado, inicialmente buscou evidenciar o perfil dos professores do ensino fundamental das séries iniciais que atuam no ensino público, preconizando suas dificuldades, suas práticas e suas expectativas sobre uma proposta de formação continuada na área das ciências naturais.

\subsection{Formação inicial}

Um dos maiores problemas na formação docente diz respeito ao desenvolvimento da sua formação inicial. Assim, alguns programas de formação de professores, conforme aponta Zeichner (1997), centram-se no practicum, que é definido por momentos da prática pedagógica, tais como estágio, aulas práticas, tutorias, enfim, toda a situação que envolva o contexto escolar na formação inicial de professores.

Para o Ministério da Educação (BRASIL, 1999), a formação inicial corresponde ao primeiro curso de formação profissional, podendo ser realizado em nível técnico (ensino médio magistério) ou em nível superior (graduação - licenciaturas). Já a formação continuada representa uma especialização cursada após a primeira formação profissional, que pode ser em nível de Pós-Graduação ou na forma de uma formação complementar, que a Secretaria da Educação ou os órgãos competentes fornecem ao profissional (neste caso, o professor), com o intuito de atualizar sua prática docente. Nessa formação, podem-se encontrar propostas de curta duração (cursos, palestras, encontros, congressos) ou cursos e ações oferecidos a longo prazo, caracterizando uma proposta de formação permanente.

No Brasil, a LDB 9394/96, Decreto número 2027, de abril de 1997, conforme apontam Freitas (2002) e Souza et al. (2003), estabelece que a formação inicial do professor ocorrerá em nível superior, podendo a instituição assumir diferentes formatos, como universidades, centros universitários, faculdades integradas, institutos superiores ou escolas superiores. Assim, profissionais da educação buscam urgentemente formar e qualificar um número grande de professores em serviço, para atender às demandas e cumprir as metas previstas pelas políticas educacionais. 
No contexto educacional brasileiro, muitos exageros foram praticados no processo de formação continuada, fato que, segundo Freitas (2002) e Souza et al. (2003), propiciou um aligeiramento na formação inicial dos professores, refletindo diretamente na sua formação continuada.

Nesse sentido, e diante de tais apontamentos, no próximo tópico será discutido como o processo de formação continuada de professores vem sendo trabalhado, nos vários contextos educacionais.

\subsection{Formação continuada}

Neste momento pretende-se apresentar algumas fundamentações sobre o papel que a escola deve desempenhar, na formação continuada dos professores. Acredita-se que esse papel norteará a formação e a prática dos professores, no contexto escolar.

Ao discutir o processo de formação continuada, Leite (2003) aponta que a escola tem como um dos seus papéis bem definidos o de produzir conhecimentos. Em decorrência, os professores são os grandes facilitadores da construção desse conhecimento, mediante a sua autoridade (não no sentido mais radical da palavra) em manejar o processo de ensino, em sala de aula. Ainda para a mesma autora (2003), o professor, juntamente com a escola, tem uma postura de educador e mediador na construção desse conhecimento e, portanto, deve se preocupar muito com o que aprende, como aprende, o que ensina, como ensina, como é seu trabalho em sala de aula e, sobretudo, com a sua formação permanente e constante.

Nessa mesma linha, Saviani (1991) enfatiza que a escola apresenta como papel principal a socialização de saberes sistematizados e existe para possibilitar ao povo o saber elaborado, ou seja, científico. A escola influencia diretamente sobre a delimitação do papel do professor, no processo de ensino e aprendizagem.

A sua função está relacionada com a sua identidade, ou seja, saber ser professor. No seu estudo, ao se referir ao papel do professor, Andrade (2003) propõe que esse profissional deve reunir vários papéis e ser eclético, de sorte que a sua profissão seja considerada algo que não se delimita a partir de uma função imposta a ele. Esse fato poderia fragilizar a sua prática em sala de aula e, conseqüentemente, a sua formação continuada.

Ao abordar a formação continuada, Dias e Lopes (2003) lembram que as políticas educacionais, em geral, mostram-se amplamente influenciadas pelos movimentos e reformas na educação, que sempre esbarram nas competências exigidas na formação docente.

Nas décadas de 1960 e 1970, segundo os mesmos autores (2003), essas competências representavam a) um modelo de estratégias metodológicas, mediante o perfil do profissional que se desejava formar; b) um perfil com base nos comportamentos desejáveis aos professores, para 
garantir a eficiência do processo de ensino e aprendizagem e c) propunham o desenvolvimento da eficiência do professor, baseada no mercado de trabalho.

Dias e Lopes (2003) e Zainko (2002) acrescentam que a formação de um profissional da área educacional deve contemplar a capacidade de exercer plenamente e com competência as atribuições que lhes foram conferidas, no processo de ensino e aprendizagem escolar. Assim, não é comum encontrar projetos de pesquisa que ofereçam aos professores educação continuada que permita a reflexão sobre sua prática pedagógica e que propicie uma mudança na sua forma de pensar e agir. Os mesmos autores (2003 e 2002) defendem que uma proposta de formação continuada de professores deva ocorrer juntamente com a função do docente, em sala de aula, para que se possa vivenciar a realidade do educador, favorecendo o desenvolvimento de pesquisas nessa área.

Preocupado com a problemática geral da formação e capacitação docente desses profissionais, nos países ibero-americanos, Carrascosa (2001) ressalta que essa iniciativa vem dependendo da vontade e disponibilidade dos professores em participar dos cursos programados pelas instituições superiores de ensino e faz um levantamento desses programas, em alguns países. Segundo o autor (2001), na Colômbia, os cursos de formação continuada podem até oferecer bolsas, créditos e ajudas aos professores que participem desses cursos de capacitação. $\mathrm{Na}$ Argentina, a formação continuada de professores depende diretamente dos próprios professores, ou seja, da vontade e da disponibilidade demonstrada em assistirem a cursos programados pelas Universidades e outras instituições formadoras de docentes. Nesse país, os centros responsáveis pela formação dos professores estão nas universidades, nas direções das escolas, em nível municipal, nos ministérios da Educação de cada província, no Ministério da Cultura e Educação Argentina e em diversas instituições privadas.

A formação continuada de professores é uma realidade independente do país ou continente analisado. São muitos os projetos, propostas e intervenções em andamento, que representam retrocessos e avanços educacionais.

Considerando essa realidade, a formação de professores de ciências vem se tornando alvo necessário para pesquisas no âmbito educacional. Os centros educacionais responsáveis pela capacitação desses profissionais acompanham as tendências internacionais de ensino de ciências, fazendo uma adaptação aos moldes brasileiros (MENEZES, 2001).

A formação continuada, no Brasil, deve seguir as necessidades de ensino e as demandas dos professores em exercício, devendo ser assegurado o trabalho de conteúdos relacionados aos diferentes âmbitos do conhecimento profissional, de forma a promover o desenvolvimento das 
competências para a atuação docente, nos momentos de formulação, planejamento e avaliação de projetos avaliativos nas escolas (BRASIL, 1999).

Os projetos de formação continuada, segundo as Diretrizes Educacionais apresentadas pelos Referenciais para a Formação de Professores e apontadas pelo Ministério da Educação (BRASIL, 1999), devem ocorrer na própria escola, em parcerias com as Secretarias de Educação e outras instituições formadoras, envolvendo o coletivo de uma ou mais escolas.

Ainda conforme aponta esse documento (BRASIL, 1999), a educação a distância surge como uma nova modalidade de formação continuada, para atender a uma grande demanda de profissionais em educação, carentes de cursos e recursos para a formação e informação. As diretrizes indicam alguns caminhos para a implantação de propostas para a formação continuada, no Brasil, porém nos levam aos seguintes questionamentos: se a proposta de formação continuada sugerida nas diretrizes parece razoável, por que ela não ocorre, na prática? Como tais propostas são conduzidas, no âmbito da formação continuada?

O problema parece estar na forma como vem sendo gerida a formação inicial e continuada, no Brasil que na maioria das vezes, esses cursos conferem conhecimento e graduam de forma rápida (sem muita dedicação do professor), de maneira seletiva, e poucos professores beneficiam-se desses cursos, restringindo a participação e a capacitação continuada para um grande efetivo do corpo docente das escolas. Sabe-se que a maioria dos cursos de formação continuada a distância extingue os momentos presenciais, imprescindíveis para um programa de formação continuada de qualidade.

Conforme propõe a Lei de Diretrizes e Bases (BRASIL, 1999), este estudo defenderá que a formação continuada deve proporcionar uma reflexão constante ao professor, em seu local de trabalho. Um repensar cotidiano sobre suas práticas, com o intuito de melhorar suas condições de trabalho e, principalmente, o sistema educacional como um todo.

Assim, para que os processos de organização, sistematização e operacionalização das ações, em uma proposta de formação continuada, ocorram de forma desejável, é preciso que se criem condições favoráveis de formação e de participação dos professores, como garantia da preservação da qualidade de ensino e formação pretendida nos documentos oficiais (BRASIL, 1999).

\section{A PESQUISA}

A pesquisa foi desenvolvida com onze professoras o ensino fundamental das séries iniciais ( $1^{\mathrm{a}}$ a $4^{\mathrm{a}}$ séries) e na própria escola (estadual) onde trabalhavam. Optou-se inicialmente pelo questionário, para se obter de forma rápida e válida os dados que formam o perfil dos profissionais que formavam o Grupo de Trabalho para as atividades propostas na pesquisa sem 
causar constrangimento para as professoras/sujeitos. A escolha do questionário possibilitou à pesquisadora obter os dados iniciais para que assim fossem definidas as etapas e atividades desenvolvidas durante toda a pesquisa.

Para o segundo momento desta pesquisa, foram realizados cinco encontros reflexivos com as professoras do ensino fundamental, das séries iniciais previamente planejados com a coordenadora da escola denominados de Grupo de Trabalho. Foram realizados quinzenalmente, de setembro à dezembro de 2005 com duas horas de duração e ocorreram logo após o horário vespertino de aula que eram disponibilizados para os $\mathrm{HTPCs}^{5}$. Todas as atividades foram filmadas, transcritas e analisadas. Esses encontros buscaram, através das necessidades educativas apresentadas pelas professoras propiciar momentos de reflexão e discussão sobre sua formação inicial e continuada.

\subsection{Procedimento de apresentação e análise dos dados}

Para analisar os dados obtidos, adotou-se a análise de conteúdo (BARDIN, 2000). A escolha deste instrumento de análise se deu por que se acredita que esta pode facilitar o entendimento das temáticas extraídas das atividades propostas para as professoras, na aplicação do questionário, durante os encontros - Grupo de Trabalho e durante todo o desenvolvimento da pesquisa. Todas as respostas do questionário foram analisadas e categorizadas em Eixos Temáticos de Análise. Neste artigo será considerado somente o primeiro Eixo Temático Formação Docente que será apresentado a seguir. Vale ressaltar que alguns trechos do primeiro episódio $^{6}$ foram retirados do Grupo de Trabalho e foram apresentados com o intuito de exemplificar de forma complementar as respostas emitidas pelas professoras.

\section{EIXO TEMÁTICO 1 - Formação docente}

\begin{tabular}{l|l}
\hline \multicolumn{1}{c|}{ SUB-EIXOS } & \multicolumn{1}{c}{ TÓPICOS DE ANÁLISE } \\
\hline & - Tempo de formação ou conclusão de curso magistério; \\
ET1.1 - Formação Inicial & - Tempo de formação do curso superior; \\
& - Curso Superior. \\
\hline \multirow{2}{*}{ ET1.2 - Formação Continuada } & - Participação de grupo de estudo; \\
& - Necessidades formativas; \\
& - Cursos de formação continuada; \\
\hline
\end{tabular}

\footnotetext{
${ }^{5}$ HTPCs é a sigla usada para determinar as horas de atividades ou trabalho pedagógico coletivo, aplicadas nas escolas estaduais e que são utilizadas para vários fins, desde o planejamento mais detalhado das atividades curriculares e pedagógicas das aulas, aconselhamento pedagógico, palestras informativas, cursos de formação, discussão sobre determinados temas, realização de grupos de trabalho e até mesmo trabalhos que nada têm a ver com as questões pedagógicas na escola (trabalhos manuais).

${ }^{6}$ Forma de transcrição: Identificação: utilizando S, para pesquisadora; Siglas de P1 a P11 para as professoras participantes do estudo; Sigla T: quando todas falam ao mesmo tempo; Sigla [R]: para as respostas e diálogos emitidos.
} 
- Órgão responsável pelo curso;

- Tempo de duração.

O Eixo Temático que se refere a Formação Docente, representa todas as questões do questionário que abordavam a formação inicial e continuada de professores da educação básica, das séries iniciais. Os Sub-Eixos, Formação Inicial e Continuada, abordam questões relacionadas ao tempo de formação, ao curso superior de formação dos professores, bem como a participação destes professores em grupos de estudo, curso de formação continuada, tempo de duração do curso e as necessidades formativas que o professor gostaria e necessitava ter.

\section{DISCUSSÃO E ANÀLISE DOS DADOS}

EIXO TEMÁTICO 1 - Formação Docente

\begin{tabular}{|c|c|}
\hline \multirow[b]{2}{*}{ SUB-EIXOS } & Tópicos de análise \\
\hline & Questionário \\
\hline \multirow{6}{*}{ ET1.1 - Formação Inicial } & a) Há quanto tempo cursou o Magistério: 11 (100\%) \\
\hline & $\begin{array}{l}\text { - Não se lembra: } 9 \% \\
\text { - Formadas entre } 26 \text { e } 30 \text { anos: } 18 \% \\
\text { - Formadas a mais de } 36 \text { anos: } 18 \% \\
\text { - Formadas entre } 31 \text { e } 35 \text { anos: } 27 \% \\
\text { - Formadas entre } 20 \text { e } 25 \text { anos: } 27 \% \\
\end{array}$ \\
\hline & b) Há quanto tempo freqüentou o Curso Superior - Graduação: 11 (100\%) \\
\hline & $\begin{array}{l}\text { - Cursando: } 9 \% \\
\text { - Acima de } 24 \text { anos: } 9 \% \\
\text { - Não informou: } 9 \% \\
\text { - De } 2 \text { a } 12 \text { anos: } 27 \% \\
\text { - De } 13 \text { a } 23 \text { anos: } 45 \% \\
\end{array}$ \\
\hline & c) Você é formada em que Curso Superior: 11 (100\%) \\
\hline & $\begin{array}{l}\text { - PEC - Formação Universitária: 9\% } \\
\text { - Normal Superior: } 9 \% \\
\text { - História - Licenciatura: 9\% } \\
\text { - Educação Artística: 9\% } \\
\text { - Ciências Físicas e Biológicas: 9\% } \\
\text { - Pedagogia: } 54 \%\end{array}$ \\
\hline \multirow{6}{*}{ SUB-EIXOS } & Tópicos de análise \\
\hline & Questionário \\
\hline & a) Você participa de algum grupo de estudo: $11(100 \%)$ \\
\hline & \begin{tabular}{|l|} 
- HTPCs: $18 \%$ \\
- Não: $36 \%$ \\
- Sim: $45 \%$ \\
\end{tabular} \\
\hline & $\begin{array}{l}\text { b) Você participou ou participa de algum curso de formação continuada: } 11 \\
(100 \%)\end{array}$ \\
\hline & $\begin{array}{l}\text { - Curso na área de Ciências: } 9 \% \\
\text { - Nenhum curso: } 9 \% \\
\text { - Curso na área da matemática: } 18 \% \\
\text { - Inclusão e temas correlatos: } 45 \% \\
\text { - Curso não especificado na Diretoria de Ensino: } 54 \% \\
\text { - Cursos na área da linguagem: } 63 \%\end{array}$ \\
\hline
\end{tabular}




\begin{tabular}{|c|c|}
\hline \multirow{6}{*}{ ET1.2 - Formação Continuada } & c) Quais as suas necessidades formativas: $11(100 \%)$ \\
\hline & $\begin{array}{l}\text { - Forneça conhecimento pedagógico: } 18 \% \\
\text { - Forneça certificado e seja gratuito: } 18 \% \\
\text { - De acordo com as necessidades pessoais: } 18 \% \\
\text { - Facilitar seu trabalho: } 27 \% \\
\text { - Ensine aulas práticas: } 54 \%\end{array}$ \\
\hline & $\begin{array}{l}\text { d) Na sua opinião quem deveria propor um curso de formação continuada } \\
\text { aos professores: } 11(100 \%)\end{array}$ \\
\hline & $\begin{array}{l}\text { - Secretaria da educação: } 9 \% \\
\text { - } \text { As universidades: } 18 \% \\
\text { - } \quad \text { SENP em parceria com as universidades: } 81 \%\end{array}$ \\
\hline & e) Qual o tempo de duração: $11(100 \%)$ \\
\hline & $\begin{array}{l}\text { - Não respondeu: } 9 \% \\
\text { - No mínimo } 30 \text { horas: } 18 \% \\
\text { - Um ano: } 72 \%\end{array}$ \\
\hline
\end{tabular}

Pode-se observar, nos dados revelados pelo questionário, que a maioria dos professores que atuam na formação básica, ou seja, no ensino fundamental das séries iniciais ( $1^{\mathrm{a}}$. a $4^{\mathrm{a}}$. séries), iniciou a sua profissão somente com um curso técnico profissionalizante, o magistério (100\%). Bastava o professor ter uma formação em nível técnico, que estava habilitado para trabalhar com o ensino fundamental das séries iniciais.

Houve uma mudança significativa, nos anos subseqüentes, pois, com a normatização dos cursos superiores para a carreira docente e em busca de melhores salários e progressão de carreira, esses professores passaram a procurar uma formação em nível universitário. Todos os professores envolvidos nesta pesquisa fizeram um curso superior, sendo que $72 \%$ deles foram graduados em cursos como Pedagogia, Normal Superior e PEC - Formação Universitária, enquanto os demais (27\%) fizeram cursos de licenciatura em áreas específicas, como História, Educação Artística e Ciências Físicas e Biológicas. Tal fato é explicável, porque, para participar de concursos de efetivação para o ensino fundamental das séries iniciais, era solicitado somente o diploma de Curso de Magistério, antigo curso profissionalizante, que, nos tempos atuais ainda é exigido como requisito mínimo para concursos, em alguns Estados.

Dentre os dados obtidos, pode-se salientar que mais de (63\%) das professoras estão atuando há mais de vinte e cinco anos na docencia. Pode-se então compreender que sua formação ainda estava pautada nos moldes dos anos 80, dentro de um modelo tradicional de ensino, no qual a escola era vista como o único meio de se adquirir uma ascensão social. Os melhores empregos eram garantidos àqueles que haviam freqüentado cursos técnicos ou profissionalizantes ou de ensino superior.

No grupo de sujeitos, mesmo a professora que está freqüentando o Curso de Pedagogia nos faz perceber que há um grande vácuo que separa a situação real de sala de aula e as situações consideradas ideais pela professora. 
S [R] Então, podemos dizer que temos as duas situações, a ideal e a real? A ideal tá lá (se referindo à faculdade) e a real está aqui (referindo-se à escola onde trabalha)!

P5 [R] É... o real está aqui (confirma com a cabeça).

P5 [R] Queremos estar no real, mas também no ideal!

Episódio 1 - Data: 27 de setembro de 2005.

Esse trecho mostra a concepção das professoras sobre um saber científico das teorias de ensino, as quais as mesmas sabem que existem, mas que desconhecem. Elas não apresentam tal conhecimento, mas sabem que ele existe. Porém, a academia está longe de conseguir levar esses conhecimentos às professoras. O seu domínio requer muito mais que conhecer essas teorias, requer que as professoras saibam o que fazer com esse saber ou conhecimento. A professora é cobrada a aplicar teorias de ensino cada vez mais complexas, em seu trabalho docente em sala de aula. Na maioria das vezes, encontramos grupos de professoras como estas, que sabem pouco a teoria, ou seja, o que lhes passaram, não de forma muito reflexiva, mas de maneira imposta, e que não conseguem aplicar tais conhecimentos em sala de aula, no seu trabalho docente.

Elas sublinham a necessidade de conhecer tais teorias, na medida em que estas forem aplicadas no contexto de sala de aula.

Como nosso interesse está na área das ciências naturais, não poderíamos deixar de salientar que essas professoras, com exceção de uma delas (9\%), que fez seu curso superior em Ciências Físicas e Biológicas (antiga Licenciatura Curta) e as que fizeram o PEC (9\%), as demais $(81 \%)$ não tiveram contato com conteúdos da área das ciências naturais.

O PEC - Formação Universitária, por ser um curso recente, propõe seu currículo baseado nas novas diretrizes curriculares, pelas quais devem ser propostos, nos Cursos de Formação de Professores do Ensino Fundamental das Séries Iniciais, conteúdos científicos em forma de disciplinas na área das ciências consideradas (Física, Química, Biologia e Matemática). Hoje, com essas novas diretrizes, os cursos de Pedagogia estão revendo seus currículos, agregando conteúdos de tais áreas, mas é algo que ainda vem sendo muito discutido.

Quando questionados sobre a sua participação em Grupos de Estudo e/ou Aperfeiçoamento Profissional, 63\% dessas professoras alegaram estar participando de um trabalho coletivo (proposto pela coordenadora pedagógica), em que faziam a leitura e a discussão de textos teóricos. Consideramos essa porcentagem, porque as professoras alegaram que os momentos destinados à leitura e discussão desses textos ocorriam durante os horários de HTPCs, na própria escola.

Com o passar do tempo, na escola, e com as observações mais pontuais das situações contextuais do local da pesquisa como um todo, ficou claro que esse grupo de estudo centrava suas atenções nas concepções pedagógicas e nas teorias interpretadas pela coordenadora 
pedagógica (que era quem comandava os momentos de discussão). Fui convidada, antes de iniciar a pesquisa, a participar de um desses momentos de HTPCs, e as professoras (em respeito à hierarquia profissional de sua coordenadora) não tinham argumento e consistência teórica para debater, contrapor ou esclarecer possíveis confusões sobre determinados conceitos que tivessem ficado expressos, na fala da coordenadora.

Ainda no Sub-Eixo Temático sobre a Formação Continuada de Professores, quando as professoras são questionadas sobre os cursos de formação de que haviam participado, nos últimos cinco anos, 63\% relataram terem freqüentado cursos na área da linguagem, ou seja, no ensino da escrita e da leitura. Pode-se observar que 54\% dessas professoras estiveram em cursos na Diretoria de Ensino, mas não conseguiram definir em qual área ou tema estes se incluíam. Esse fato nos permite concluir que a maioria dos cursos promovidos pela Diretoria de Ensino é muito ampla, geral e superficial, pois as professoras nem sequer se lembram do temas correlatos propostos por eles.

O trecho, a seguir, exemplifica o desenvolvimento desses cursos, na concepção das próprias professoras.

P2 [R] Depende de uma coisa... de acordo com o que você tá fazendo... é que nós temos uma frustração... Em todos esses anos que você viu nesse perfil do trabalho, quando vai em um curso, não se pode trocar idéias.... Em HTPC, não se troca idéia... O que eu acho que nem o que a gente faz de porta em porta... (sinalizando que troca idéia com a colega, no corredor da escola). Quando eu trabalhava com ela (e aponta para P1) eu trocava idéia com ela... Essa necessidade de falar... essa chance de falar... Hoje ficou tudo muito correndo.

P1 [R] Um curso que nós fizemos juntas (e apontou para P2), eu e ela. Inclusive nós fomos convidadas a nos retirar do curso várias vezes.

S [R] Que curso?

$\mathrm{P} 2[\mathrm{R}]$ Letra e vida.

$\mathrm{S}[\mathrm{R}]$ Aliás, foi o curso mais citado. E pelo que percebi é bem longo.

$\mathrm{P} 2[\mathrm{R}]$ Mas não é bem sobre as expectativas desse curso.

P5 [R] Eu tô terminando ... mas, meu pai do céu.

$\mathrm{S}[\mathrm{R}]$ Tem duração de quanto tempo?

P5 [R] Um ano e meio.

$S$ [R] Mas é um curso do quê? Pós-Graduação. Formação, curso.

P2 [R] É um curso de Pós-Graduação, mas deixando em negrito, né. P1 (e olha para P1), que você consegue arrancar água de pedra!!! Não é?

$\mathrm{S}[\mathrm{R}]$ Escuta... oferece certificado?

P2 e P9 [R] Até agora, não vimos nada.

P5 [R]Até agora nada... mas a nossa coordenadora vai dar um jeito, né!

$\mathrm{S}[\mathrm{R}]$ Quem fez?

P2 [R] Eu, ela (aponta para P1) e a P6 e P11(e aponta para ambas com o indicador). 


\section{$\mathrm{S}[\mathrm{R}] \mathrm{E}$ ponto? Conta ponto?}

P6 e P2 [R] Até agora, nada... (afirmam negativamente com a cabeça).

P6 [R] Nem coquetel que me falaram que tinha.... no coquetel, nós vamos comer salgadinho frio... e coca quente é daqui de casa (fala com sotaque nordestino).

[Houve um momento de descontração... e risada no grupo, da forma como P6 se colocou... mas a professora não se sentiu envergonhada...]

Episódio 1 - Data: 27 de setembro de 2005.

As professoras apontam suas frustrações sobre a falta de diálogo nas escolas, entre professores, entre professores e coordenadores ou orientadores pedagógicos, e também com as pessoas com cargos superiores, como diretores e supervisores de ensino, que se colocam nas diretorias de ensino. Tal situação se torna um obstáculo na formação continuada dessas professoras, que pode ser observado quando relatam suas participações em cursos da diretoria de ensino e de que, na maioria das vezes, são convocadas para participar, sem serem informadas sobre as atividades que serão desenvolvidas nessas ocasiões e sobre como poderão se beneficiar com eles. Esse fato pode ser verificado na ilustração abaixo, propiciada por um trecho retirado das falas das professoras, no Grupo de Trabalho.

$\mathrm{S}[\mathrm{R}]$ Vocês foram convidadas para fazer o curso?

P2 [R] Não. Nós fomos obrigadas a fazer (se referindo às professoras efetivas), mas agora nós, ACTs (forma como são chamadas as professoras não concursadas, no exercício da profissão no Estado), fazíamos se quiséssemos fazer.

S [R] Quantas horas têm o curso?

$\mathrm{P} 2[\mathrm{R}]$ Acho que 180 horas.

P8 [R] Talvez 280 horas.

Episódio 1 - Data: 27 de setembro de 2005.

Percebe-se, na fala de P5, a necessidade de dialogar entre os professores. Essa troca de experiência é uma fonte muito importante de aquisição de saberes, proveniente da sua prática, e que deve ser considerada. Um outro fator importante ainda sobre a formação continuada e que merece ser exemplificado pela fala das professoras, é que há uma marcante falta de interação entre as professoras e os profissionais de educação que trabalham na Secretaria da Educação e Diretoria de Ensino. A passagem a seguir ilustra a forma como os professores são levados a participar dos cursos propostos, os quais contam com a presença de alguns membros das instâncias acima mencionadas:

P2 [R] Não, são coisas que mantêm a dúvida. É que nós... nós aqui...(aponta P1) principalmente, entrou no curso da CENP, com a moça da CENP.

P1 [R] Não, eu não fiquei.... Eu simplesmente fui me colocar numa situação e tinha uma pessoa estranha na sala que eu não sabia quem era. $\mathrm{E}$ era a própria $\mathrm{X}$ ? (citam o nome da coordenadora da CENP) que nem esperou eu concluir... e que tava com um pé atrás comigo e com ela (e aponta para P2) e já falaram aquelas 
duas... Bom, ela deu pau em mim... (fez gesto de paulada). Esperaí, em primeiro lugar eu sou P1, trabalho em tal escola, professora... e quem é você?

P2 [R]Aí ela arrepiou (se referindo à profissional da Secretaria da Educação).

P1 [R]Falei desse jeito... Ah.. eu sou?... muito prazer.

P2 [R] Porque é assim mesmo no Estado!

$\mathrm{P} 1[\mathrm{R}]$ Em primeiro lugar, você nem me deixou concluir o que eu tava dizendo. Em segundo lugar, nós todos trabalhamos com crianças, somos todos adultos e eu vou falar o que eu penso!

P6 [R] Vou falar o quê?

P1 [R] Vou falar o que eu penso! Aí eu falei.

Episódio 1 - Data: 27 de setembro de 2005.

Observa-se que a hierarquia presente entre os profissionais da área da educação influencia ou delimita o desenvolvimento dos cursos de aperfeiçoamento profissional, propostos aos professores. Estes, na maioria das vezes, são levados a realizar esses cursos sem que manifestem seus questionamentos e, quando o fazem, são convidados a se retirar. Os cursos são avaliados seguindo esses mesmos preceitos, ou seja, os professores, ao serem avaliados, não podem emitir suas próprias conclusões sobre as atividades propostas. No trecho a seguir, podemos ver uma exemplificação clara sobre as formas de avaliação dos cursos de formação continuada, organizados pela Secretaria de Educação ou pela Diretoria de Ensino:

$\mathrm{S}[\mathrm{R}]$ Teve avaliação no curso?

P2 [R] Não... Inclusive a prova era assim... se você respondesse algo que não batesse, tinha que ser refeita.... Isso. Eu não tenho medo de falar, tal... não é? (e aponta para a colega da sala P6).

P6 [R] É.

P2 [R] As respostas não eram de acordo com as metas do curso... aí eles (se referindo à Diretoria de Ensino) orientavam para responder igual.

P6 [R] Não queriam saber sua opinião pessoal, tem que ser o be-a-bá deles (se referindo à CENP).

Episódio 1 - Data: 27 de setembro de 2005.

Ao serem questionadas sobre as necessidades formativas para os conteúdos de ciências, na visão dessas professoras, 54\% colocam no questionário inicial que, para trabalhar com conteúdos de ciências, deveriam ser oferecidos cursos de formação continuada que enfocassem aulas práticas. As professoras chamam de aulas práticas os experimentos realizados por elas, nas aulas de ciências. Acreditam que, por falta de conhecimento sobre os conteúdos de ciências, seu trabalho em sala de aula fica restrito às atividades fixadas pelos livros didáticos, de sorte que continuam reproduzindo os experimentos apresentados por esses livros, sem conseguir ousar muito nas atividades que envolvem experimentos de ciências.

As atividades surgem com o intuito de comprovar (na forma de aulas práticas) alguns conceitos estabelecidos pelos livros didáticos. Esse fato não é muito diferente daqueles 
vivenciados pelos professores de ciências do ensino fundamental de $5^{\mathrm{a}}$. a $8^{\mathrm{a}}$. séries e ensino médio, conforme a própria observação de alguns pesquisadores da Área de Ensino de Ciências.

Os cursos de formação continuada, na concepção dessas professoras $(81 \%)$, deveriam ser oferecidos por parceria da Secretaria Estadual de Educação com as Universidades. Tal sugestão demarca o interesse dessas professoras em participar de ações e/ou atividades que envolvam o mundo acadêmico. Não suprimem do Estado a obrigação de fornecer aos seus profissionais uma formação mais concisa, e esse fato evidencia também o saber elaborado (científico) produzido pelas universidades, sem indicar, entretanto, se essas universidades são privadas ou públicas.

O tempo de duração de um curso de formação continuada, na visão dessas professoras (72\%), deveria ser de um ano e, de preferência, que oferecessem certificado de conclusão, recomendação que nos mostra qual a concepção de formação continuada essas professoras possuem. Ao que tudo indica, compreendem sua formação continuada como sendo uma formação (gradual - em nível de graduação) complementar, curta, rápida, destinada a lidar com problemas pontuais.

\section{ALGUMAS CONSIDERAÇÕES}

Entende-se que a formação continuada, como o próprio nome diz, deva ocorrer continuamente e que não se restrinja a solucionar problemas advindos da formação inicial dos professores. Precisa ser disponibilizada de maneira permanente, e os professores, por decisão própria, possam freqüentar, para aperfeiçoar sua formação e atuação.

Ainda são muito confusas, para as professoras, todas essas questões. Os problemas enfrentados pela estrutura escolar e as características intervenientes (culturais, sociais e legais) demarcam, ao longo de suas carreiras, a sua formação continuada, sua prática pedagógica e sua profissão.

O ensino fundamental das séries iniciais é uma etapa de escolarização das crianças, que ficam alheias ao ensino de conteúdos específicos, colocando-se, assim, fora das pesquisas e projetos que envolvam essas áreas.

Tanto no questionário, quanto no primeiro episódio analisado, fica evidente que as professoras apresentam muitas dificuldades para abordar conteúdos de ciências: primeiramente, pela falta de conhecimento desses conteúdos; segundo, pela cobrança mais efetiva, por parte do Estado, dos conteúdos relacionados à escrita e à leitura; e, em terceiro e último lugar, pelas poucas ações efetivas para a formação continuada destinada à área das ciências naturais.

\section{REFERÊNCIAS BILBIOGRÁFICAS}

BARDIN, L. Análise de conteúdo. Lisboa: Edições 70, 2000. p.225.

BRASIL. Ministério da Educação. Referenciais para a formação de professores. Secretaria de Educação Fundamental. Brasília. A Secretaria, 1999. 
CARRASCOSA, J. Análise da formação continuada e permanente de professores de ciências ibero-americanos. In: MENEZES, L. C. Formação continuada de professores de ciências no âmbito ibero-americano. 2ed, Campinas, SP: Autores Associados; São Paulo, SP: NUPES, 2001. p.07 - 44. (Coleção formação de professores).

DIAS, R. E. \& LOPES, A.C. competências na formação de professores no Brasil: o que (não) há de novo. Revista Educação e Sociedade, v.24, n.85, p.1155-1177, dez., 2003.

FREITAS, H.C.L. de. A formação dos profissionais da educação básica em nível superior: desafios para as Universidades, Faculdades/Centros de Educação. In: GARCIA, W.G.

Pedagogia Cidadã, Cadernos de Formação: Módulo Introdutório. São Paulo: Editora da UNESP, 2002. p.09-26. 145p.

LEITE, L.P. A intervenção reflexiva como instrumento de formação continuada do educador: um estudo em classe especial. Marília, 2003. 212p. (Tese de Doutorado em Educação, Faculdade de Filosofia e Ciências, Universidade Estadual Paulista).

SAVIANI, D. Pedagogia Histórico-Crítica: primeiras aproximações. São Paulo: Cortez, 1991.

SOUZA, M.F.A.; ENS, R.T. \& FILIPAK, S.T. Diretrizes curriculares para a formação de professores. In: EYNG, Ana Maria; ENS, Romilda Teodora \& JUNQUEIRA, Sérgio Rogério Azevedo (Coord.) O tempo e o espaço na educação: a formação do professor. Curitiba: Champagnat, 2003. p.135-146. 175p.

ZAINKO, M.A.S. Dos saberes às competências: construindo um novo processo de formação. Revista Diálogo Educacional, v.3, n.5, p.29-48 jan./abril, 2002.

ZEICHNER, K. Novos caminhos para o practicum: uma perspective para os anos 90. In: In: NÓVOA, A. (Coord). Os professores e a sua formação. Lisboa: Dom Quixote, 1997. p. 115-138.

ANDRADE, L.T. de. A escrita dos professores: textos em formação, professores em formação, formação em formação. Revista Educação e Sociedade, v.24, n.85, p.1297-1315, dez., 2003.

MENEZES, L.C. Características convergentes no ensino de ciências nos países ibero-americanos e na formação de seus professores. In: MENEZES, L.C. Formação continuada de professores de ciências no âmbito ibero-americano. 2ed, Campinas, SP: Autores Associados; São Paulo, SP: NUPES, 2001. p.45-58. (Coleção formação de professores). 